\title{
Prevalence of Oral Mucosal Lesions in an Adult Iranian Population
}

\author{
Fariborz Mansour Ghanaei ${ }^{1,}$, Farahnaz Joukar ${ }^{1}$, Maryam Rabiei ${ }^{1}$, Alireza Dadashzadeh ${ }^{1}$, \\ Ali Kord Valeshabad ${ }^{1}$ \\ ${ }^{1}$ Gastrointestinal and Liver Diseases Research Center (GLDRC), Guilan University of Medical Sciences, Rasht, IR Iran \\ *Corresponding author: Fariborz Mansour Ghanaei, Gastrointestinal and Liver Diseases Research Center (GLDRC), Guilan University of Medical Sciences, Razi hospital, Rasht, IR Iran. \\ Tel.: +98-131535116, Fax:+98-1315534951, E-mail: ghanaei@gums.ac.ir.
}

Received: February 26, 2012; Revised: January 14, 2013; Accepted: Jun 11, 2013

\begin{abstract}
Background: Nowadays the importance of oral health to life quality is not obvious to anyone in our world. Oral lesions can interfere with daily social activities in involved patients through impacts on mastication, swallowing and speech and symptoms like xerostomia, halitosis or dysesthesia.

Objectives: To assess the prevalence and types of oral lesions in a general population in Rasht, Northern Province of Iran.

Patients and Methods: 1581 people aged > 30 years old who were inhabitant of Rasht, Iran, enrolled in a cross-sectional study. For each individual a detailed questionnaire based on the world health organization (WHO) guidelines in order to diagnosis of the lesions was filled and it contained all the required data. Participants were divided into two groups with and without oral mucosal lesions and oral mucosal lesions were divided into two groups with and without. Demographic characteristics and clinical information including age, sex smoking (cigarette and tobacco), opium consumption, medication and oral and dental hygiene were collected and compared between these two groups.

Results: The prevalence of mucosal lesions in our study was 19.4\%. Our data demonstrated higher prevalence of oral mucosal lesions in males and young adults (30-40 years). The most common mucosal lesion among our participants was Fissured tongue(4\%), followed by Fordyce granules(2.8\%), geographic tongue(2.6\%), Pigmentation(2.5\%), Candida(1.8\%), Smoker Plate(1.6\%), lingual Varices(1.5\%), Petechiae(1.4\%) and lingual labial(1.4\%). Leukoplakia was observed only in two people(0.1\%).No case of malignant lesions was detected. No statistically significant difference was confirmed between the two groups regarding smoking, opium consumption, medication and oral and dental hygiene.

Conclusions: Our data has provided baseline information about epidemiologic aspects of oral mucosal lesions which can be valuable in organized national program targeting on oral health and hygiene in the society.
\end{abstract}

Keywords: Mouth Mucosa; Adult; Iran

\section{Background}

Nowadays the importance of oral health to life quality is not obvious to anyone in our world. Oral lesions can interfere with daily social activities in involved patients through impacts on mastication, swallowing and speech and symptoms like xerostomia, halitosis or dysesthesia (1). Oral cavity was classified as one of the most common ten malignancies from 1975 to 2006 (2). High risk habits such as alcohol and tobacco consumption have been recognized as defined causes for oral precancerous or cancerous lesions $(3,4)$. Despite the lack of definite evidence supported in the literatures, some dental factors such as improperly fitting denture, electrogalvanism, edentulism, sharp teeth, mouthwashes and poor oral hygiene have been announced as probable causes of oral precancerous and cancerous lesions $(5,6)$. Epidemiological as says declare a wide variety in the prevalence and most common types of oral lesions in various regions of the world. The prevalence of these lesions in general population has been reported 9.7\% in Malaysia (7), 15.5\% in Turkey (8), $25 \%$ in Italy 4 and $61.6 \%$ in Slovenia (9). These lesions have been found in $15 \%$ of Saudi Arabian (10) and $41.2 \%$ of Indian (11) dental patients.

The extracted data from these oral health surveys are essential for preparing health strategies in the community. Furthermore, to our knowledge except one published study with our group about status of oral lesions and dental disorders in elderly people (12), there is no other study about the epidemiology of all oral lesions in Iran and most of the conducted studies included only tumors and ulcers or biopsy specimens or just

Implication for health policy/practice/research/medical education:

There is no other study about the epidemiology of all oral lesions in Iran and most of the conducted studies included only tumors and ulcers or biopsy specimens or just some of the oral lesions in dental patients 13,14. There is a great sense of needs in Iran for establishing a baseline set of data toward the prevalence of oral lesions in general population.

Copyright (C) 2013, Iranian Red Crescent Medical Journal; Licensee Kowsar Ltd. This is an Open Access article distributed under the terms of the Creative Commons Attribution License (http://creativecommons.org/licenses/by/3.0), which permits unrestricted use, distribution, and reproduction in any medium, provided the original work is properly cited. 
some of the oral lesions in dental patients $(13,14)$. There is a great sense of needs in Iran for establishing a baseline set of data toward the prevalence of oral lesions in general population.

\section{Objectives}

This study is designed to assess the prevalence and types of oral lesions in a general population in Rasht, Northern Province of Iran.

\section{Patients and Methods}

In this cross-sectional study, 1581 people aged $>30$ years who were inhabitants of Rasht, Iran were enrolled in the study. Multisession cluster method was applied for sampling from general population in this city. For performing the research, 2 trained health specialists as interviewers went to people's houses and explained the objectives of the survey for people aged $>30$ years old ,in the case of agreement for participation a card for referring to the supposed dental clinic for more examination was given to them. Each participant gave informed consent before enrolling in the study in clinic. Those without an informed consent were excluded from the study. A detailed questionnaire based on the world health organization (WHO) guidelines was filled by the interviewers for each individual which contained all the required data in order to diagnosis of the lesions.

Selected participants underwent complete clinical oral examination by three general dentists who were trained by dental specialist with an intra-examiner agreement upper than $95 \%$ and all the information about the type of the lesions and their location (Gingiva, lip, tongue or oral mucosal tissue) were recorded in the questionnaire. Participants were divided into two groups with and without oral mucosal lesions. Oral lesions were divided into two groups: 1) white color lesions including leukoplakia, Leukoedema, lichen planus, smokers` plate, Frictional Keratosis, Candida, Fordyce granules, traumatic ulcers and recurrent aphthous; 2) nonwhite lesions of oral mucosa including herpes labial, Fissured Tongue, geographic tongue, , Hairy tongue, Periapical cyst, Infected tooth related cyst, Pigmentation, Lingual Varices, and Petechiae. Those lesions that could not be diagnosed by clinical examination were just analyzed through histopathological study. A specific code and card were designed for patients with white color lesions that they underwent a histopathological study and these patients were told to return for their final diagnosis based on the biopsies. Demographic characteristics and clinical information including age, sex, smoking (cigarette and tobacco), opium consumption, medication and oral and dental hygiene (use of toothbrush, toothpick, dental floss, mouthwashes, number of filled or decayed tooth) were collected and compared between these two groups. The study protocol was approved by ethics committee of Gastrointestinal and Liver Diseases Research Center of Guilan University of Medical Sciences.

\subsection{Statistical Analysis}

The Kolmogorov-Smirnov test (KS-test) was assigned to assess the normal distribution of the data. Results were reported as mean \pm standard deviation (SD) for quantitative variables and percentages for categorical variables. The groups were compared using the Student's t- test for continuous variables and the chi-square test (or Fisher's exact test if required) for categorical variables. P values of 0.05 or less were considered statistically significant. All the statistical analyses were performed using SPSS version 16 (SPSS Inc, Chicago, IL, USA) for Windows.

\section{Results}

From 1581 individuals who were enrolled in the study, 306 people (19.4\%) had 416 (26.3\%) different types of oral lesion. One or more oral mucosal lesions were found in 306 people. Demographic characteristics and baseline clinical data of the participants and their comparisons between two groups are summarized in Table 1. Table 2 shows the frequency and prevalence of various types of oral lesions in our people. The places of these detected lesions are shown in Table 3.

Malignant lesions weren't found in any participants, either squamous cell carcinoma or adenocarcinoma. Family history of oral cancer, tongue cancer, soft plate and oral cavity were found in 2 (0.1\%), 4 (0.3\%), 2 (0.1\%) and $1(0.1 \%)$ of the participants. It is necessary to mention all of them had no oral lesions.

\section{Discussion}

Despite the considerable prevalence of oral mucosal lesions and their subsequent morbidity in the involved patients, there is no large scaled population-based study regarding prevalence and pattern of these lesions in the society. Our data demonstrated higher prevalence of oral mucosal lesions in males (55.8\%) and young adults (30-40 years) (53.9\%). However in some studies their prevalence has been found to be higher in older individuals $(15,16)$ and females (10).Across different regions of the world the frequency and types of oral soft tissue lesions vary. The prevalence of oral mucosal lesions in our study was $19.4 \%$ which was considerably lower than what Rabiei M et al. found in institutionalized elderly people in Rasht, 
Mansour Ghanaei Fet al.

Table 1. Demographic Characteristics and Clinical Data of the Participants

\begin{tabular}{|c|c|c|c|}
\hline Variables & With Oral lLsion $(n=306)$ & Without Oral Lesion $(n=1275)$ & P Value \\
\hline Male gender & $171(55.9)$ & $668(52.4)$ & 0.27 \\
\hline Mean age (year) & $42.4 \pm 13.7$ & $40.9 \pm 11.5$ & 0.71 \\
\hline \multicolumn{4}{|l|}{ Age groups } \\
\hline$<40$ & 165 (53.9) & $671(52.6)$ & \\
\hline $40-50$ & $67(21.9)$ & $356(27.9)$ & \\
\hline $50-60$ & $38(12.4)$ & $160(12.5)$ & 0.00 \\
\hline $60-70$ & $22(7.2)$ & $68(5.3)$ & \\
\hline$>70$ & $14(4.6)$ & $20(1.5)$ & \\
\hline Denture & $83(27.1)$ & $371(29.1)$ & 0.49 \\
\hline Tooth decay & $135(44.1)$ & $544(42.7)$ & 0.65 \\
\hline Filled tooth & $194(63.3)$ & $820(64.3)$ & 0.77 \\
\hline Toothbrush & $272(88.9)$ & $1146(89.9)$ & 0.61 \\
\hline Toothpick & $69(22.5)$ & $323(25.3)$ & 0.32 \\
\hline Dental floss & $102(33.3)$ & $411(32.2)$ & 0.71 \\
\hline Mouthwash & $19(6.2)$ & $77(6.0)$ & 0.91 \\
\hline Medication & $79(25.8)$ & $304(23.8)$ & 0.45 \\
\hline Cigarette smoking & $44(14.4)$ & $178(14.0)$ & 0.85 \\
\hline Tobacco smoking & $13(4.2)$ & $45(3.5)$ & 0.55 \\
\hline Opium consumption & $7(2.3)$ & $28(2.1)$ & 0.92 \\
\hline
\end{tabular}

Table 2. Frequency and Prevalence of Oral Mucosal Lesion

\begin{tabular}{|c|c|c|c|c|c|}
\hline White color lesion & $\begin{array}{l}\text { Frequency, No. (\%) } \\
(\mathrm{N}=416)^{\mathrm{a}}\end{array}$ & $\begin{array}{l}\text { Prevalence, \% } \\
(\mathbf{N}=\mathbf{1 5 8 1})\end{array}$ & Nonwhite color lesion & $\begin{array}{l}\text { Frequency, No. (\%) } \\
(\mathrm{N}=416)\end{array}$ & $\begin{array}{l}\text { Prevalence, No. \% } \\
(\mathrm{N}=1581)\end{array}$ \\
\hline Fordyce granules & $44(10.6)$ & 2.8 & Fissured tongue & $64(15.3)$ & 4 \\
\hline Candida & $29(6.9)$ & 1.8 & Geographic tongue & $41(9.9)$ & 2.6 \\
\hline Smoker plate & $26(6.3)$ & 1.6 & Pigmentation & $39(9.4)$ & 2.5 \\
\hline $\begin{array}{l}\text { Stomatitis recur- } \\
\text { rent aphthous }\end{array}$ & $21(5)$ & 1.3 & Lingual Varices & $24(5.8)$ & 1.5 \\
\hline Frictional keratosis & $14(3.4)$ & 0.9 & Petechiae & $22(5.3)$ & 1.4 \\
\hline Oral lichen planus & $12(2.9)$ & 0.7 & Herpes labial & $22(5.3)$ & 1.4 \\
\hline Leukoedema & $8(1.9)$ & 0.5 & Hairy tongue & $14(3.4)$ & 0.9 \\
\hline \multirow[t]{2}{*}{ Leukoplakia } & $2(0.5)$ & 0.1 & Periapical cyst & $7(1.7)$ & 0.4 \\
\hline & & & Infected tooth related cyst & $4(0.9)$ & 0.2 \\
\hline
\end{tabular}

${ }^{\mathrm{a}}$ There were 416 oral lesions in 306 people

Table 3. Site of Oral Mucosal Lesions Among 1581 Participants

\begin{tabular}{ll}
\hline Site of the lesion & $\mathbf{N}=\mathbf{4 1 6}(\%)$ \\
\hline Tongue & $158(10)$ \\
\hline Gingiva & $87(5.5)$ \\
Lip & $60(3.8)$ \\
Oral base & $51(3.2)$ \\
Soft palate & $26(1.6)$ \\
Buccal mucosa & $16(1.01)$ \\
Sublingual & $12(0.8)$ \\
Vestibule & $4(0.3)$ \\
Ridge & $2(0.1)$
\end{tabular}

Iran (12), and some other studies in other countries $(9,11)$, but it is interesting to know that it was higher than their prevalence in some other countries $(2,7,8,10)$. The most common mucosal lesion among our participants was fis- sured tongue (4\%), followed by Fordyce granules (2.8\%), geographic tongue $(2.6 \%)$ and pigmentation (2.5\%). This finding is in consistence with study by Dos Santos et al. (17), however other investigations have reported Fordyce granules (9), melanin pigmentation (18), fibrous dysplasia (19), varices (16) and coated tongue 6 as the most common oral lesions.

Tongue lesions possessed a considerable proportion of oral mucosal lesions with different prevalence rate in various parts of the world $(16,20,21)$. In our study tongue lesions were observed in $10 \%$ of the participants which were higher than previously published study (2, $6,8,10)$. The prevalence of fissured tongue as a common tongue condition is ranges from 5.2\% among Turkes (18), 5.7\% among the Indians (11), 21\% among the Slovenians (9), 27.5\% in the Amazonians (17) and 28\% among elderly in This (16). Fordyce granules were found in $2.8 \%$ of our patients while in a study by Kovoc-Kovocic and Skaleric in 
Slovenia it was found as the most common oral condition by a considerable prevalence (49.7\%) (9). this lesion was found common in dental patients in Saudi Arabia (3.8\%) $(2,10)$ And southern India (11), while it was not so common in Iranian elderly people (12). The third and fourth common oral lesions among our participants were geographic tongue and pigmentation. In an assessment of 243 Spanish children, geographic tongue (4.48\%) found as third common lesions of the oral mucosa subsequent subdural tongue (16.02\%) and traumatisms (12.17\%) (20). Two other studies reported a high frequency for geographical tongue in the north of Iran $(13,14)$. Mumcu $G$ et al. in a study in Turkey confirmed melanin pigmentation as the most common mucosal lesions in Turkish people (18).

Leukoplakia was observed only in two people (0.1\%) in our study which it was considerably lower than the expected range of $1 \%$ to $5 \%$ (22) also the prevalence rate in other studies was low $(2,10,11)$ while the prevalence of lichen planus (0.7) was in the estimated range of $0.1 \%$ to $2.2 \%$ for general population (23). In an agreement with population-based studies in Slovenia (9) and Greece (1), the results of our studies indicated no case of malignant lesions in the studied population while cases of squamous cell carcinoma and adenocarcinoma have been reported in other similar studies with various prevalence rates $(6,7,17)$. Associations between oral mucosal lesions, alcohol and tobacco smoking have been illustrated in several studies $(2,4)$ and it has been indicated that oral lesions would increase with age in association with tobacco consumption and denture use (24). In contrast, among our participants there was not a significant difference toward tobacco consumption between participants with and without oral lesions $(\mathrm{P}=0.85)$ and oral lesions were more common in the age group of 30-40 years. Other factors such as trauma, medications and oral and dental hygiene have been found to play a role in oral mucosal changes and diseases (25). No statistically significant difference was confirmed between our participants with and without oral lesions regarding smoking (cigarette and tobacco), opium consumption, medication and oral and dental hygiene (use of toothbrush, toothpick, dental floss, mouthwashes, number of filled or decayed tooth) $(\mathrm{P}>0.05)$. Our data has provided baseline information about epidemiologic aspects of oral mucosal lesions that can be valuable in organized national program targeting on oral health and hygiene in the society.

\section{Acknowledgements}

We would like to thank all the Gastrointestinal \& Liver Diseases Research Center (GLDRC) personals.

\section{Authors' Contribution}

All authors contributed equally.

\section{Financial Disclosure}

There is no financial disclosure.

\section{Funding/Support}

This study was supported in part by a grant from the Iranian Cancer Research Network and the Gastrointestinal \& Liver Diseases Research Center.

\section{References}

1. Triantos D. Intra-oral findings and general health conditions among institutionalized and non-institutionalized elderly in Greece. J Oral Pathol Med. 2005;34(10):577-82.

2. Al Dosari AM. Preliminary study of oral cancer in Saudi Arabia. Saudi Med J.1987;8(5):476-480.

3. Jahanbani J. Prevalence of oral leukoplakia and lichen planus in 1167 Iranian textile workers. Oral Dis. 2003;9(6):302-4.

4. Pentenero M, Broccoletti R, Carbone M, Conrotto D, Gandolfo S. The prevalence of oral mucosal lesions in adults from the Turin area. Oral Dis. 2008;14(4):356-66.

5. Reichart PA. Oral mucosal lesions in a representative cross-sectional study of aging Germans. Community Dent Oral Epidemiol. 2000;28(5):390-8.

6. Campisi G, Margiotta V. Oral mucosal lesions and risk habits among men in an Italian study population. J Oral Pathol Med. 2001;30(1):22-8.

7. Zain RB, Ikeda N, Razak IA, Axell T, Majid ZA, Gupta PC, et al. A national epidemiological survey of oral mucosal lesions in Malaysia. Community Dent Oral Epidemiol. 1997;25(5):377-83.

8. Cebeci AR, Gulsahi A, Kamburoglu K, Orhan BK, Oztas B. Prevalence and distribution of oral mucosal lesions in an adult Turkish population. Med Oral Patol Oral Cir Bucal. 2009;14(6):E272-7.

9. Al-Mobeeriek A, AlDosari AM. Prevalence of oral lesions among Saudi dental patients. Ann Saudi Med. 2009;29(5):365-8.

10. Kovac-Kovacic M, Skaleric U. The prevalence of oral mucosal lesions in a population in Ljubljana, Slovenia. J Oral Pathol Med. 2000;29(7):331-5.

11. Mathew AL, Pai KM, Sholapurkar AA, Vengal M. The prevalence of oral mucosal lesions in patients visiting a dental school in Southern India. Indian J Dent Res. 2008;19(2):99-103.

12. Rabiei M, Kasemnezhad E, Masoudi rad H, Shakiba M, Pourkay $\mathrm{H}$. Prevalence of oral and dental disorders in institutionalised elderly people in Rasht, Iran. Gerodontology. 2010;27(3):174-7.

13. Rabiei M, Mohtashamamiri Z, Amigh S, Ghotbirad SF, Ahsani Tehrani S. Prevalence of geographic tongue, fissure tongue and partial ankyloglossia among students of three stages of school in Rasht in 2003. J Islamic Dent Assoc Iran. 2006;18(1):30-6.

14. Rabiei M, Mohtashame Amiri Z, Masoodi Rad H. Frequency of tongue anomalies in primary school of Lahidzan. J Med Facul Guilan Univ Med Scie. 2003;45:42-36.

15. Scott J, Cheah SB. The prevalence of oral mucosal lesions in the elderly in a surgical biopsy population: a retrospective analysis of 4042 cases. Gerodontology. 1989;8(3):73-8.

16. Jainkittivong A, Aneksuk V, Langlais RP. Oral mucosal conditions in elderly dental patients. Oral Dis. 2002;8(4):218-23.

17. dos Santos PJ, Bessa CF, de Aguiar MC, do Carmo MA. Crosssectional study of oral mucosal conditions among a central Amazonian Indian community, Brazil. J Oral Pathol Med. 2004;33(1):7-12

18. Mumcu G, Cimilli H, Sur H, Hayran O, Atalay T. Prevalence and distribution of oral lesions: a cross-sectional study in Turkey. Oral Dis. 2005;11(2):81-7.

19. Bornstein MM, Luond-Valeskeviciute I, Altermatt HJ, Stauffer E, Buser D. [Oral mucosal lesions diagnosed in a stomatology service. An examination of clinico-pathological findings from the year 2003]. Schweiz Monatsschr Zahnmed. 2006;116(5):468-75.

20. Avcu N, Kanli A. The prevalence of tongue lesions in 5150 Turkish dental outpatients. Oral Dis. 2003;9(4):188-95.

21. Garcia-Pola Vallejo MJ, Martinez Diaz-Canel AI, Garcia Martin JM, Gonzalez Garcia M. Risk factors for oral soft tissue lesions in an adult Spanish population. Community Dent Oral Epidemiol. 2002;30(4):277-85.

22. Mallo L, Gerardo-Rodriguez G, Goiriena FJ, Lafuente R. Pathol- 
ogy of the oral mucosa in the Spanish institutionalized elderly. Med Oral. 2000;5(3):177-86.

23. Jungell P. Oral lichen planus. A review. Int J Oral Maxillofac Surg. 1991;20(3):129-35.

24. Shulman JD, Beach MM, Rivera-Hidalgo F. The prevalence of oral mucosal lesions in U.S. adults: data from the Third National Health and Nutrition Examination Survey, 1988-1994. J Am Dent Assoc. 2004;135(9):1279-86.

25. Salem G. Leukoplakia and tobacco habits in Gizan, Saudi Arabia. Saudi Dent J.1992;4(2):50-4. 